\title{
Human Endogenous Retrovirus W Activity in Cartilage of Osteoarthritis Patients
}

\author{
Signy Bendiksen, ${ }^{1}$ Inigo Martinez-Zubiavrra, ${ }^{2}$ Conny Tümmler, ${ }^{3}$ Gunnar Knutsen, ${ }^{4}$ \\ Jan Elvenes, ${ }^{4}$ Elisabeth Olsen, ${ }^{3}$ Randi Olsen, ${ }^{5}$ and Ugo Moens ${ }^{6}$ \\ ${ }^{1}$ Department of Laboratory Medicine, University Hospital of North Norway, Sykehusveien 38, 9038 Troms $\emptyset$, Norway \\ ${ }^{2}$ Department of Clinical Medicine, Faculty of Health Sciences, University of Tromsø, MH-Building, 9037 Tromsø, Norway \\ ${ }^{3}$ Genøk Centre of Biosafety, Science Park, Sykehusveien 23, 9294 Tromsø, Norway \\ ${ }^{4}$ Department of Orthopaedics, University Hospital of North Norway, Sykehusveien 38, 3098 Tromsø, Norway \\ ${ }^{5}$ Department of Electron Microscopy, Institute of Medical Biology, Faculty of Health Sciences, University of Tromsø, Sykehusveien 44, \\ 9037 Tromsø, Norway \\ ${ }^{6}$ Department of Medical Biology, Faculty of Health Sciences, University of Tromsø, MH-Building, 9037 Tromsø, Norway
}

Correspondence should be addressed to Ugo Moens; ugo.moens@uit.no

Received 7 March 2014; Accepted 25 June 2014; Published 22 July 2014

Academic Editor: Anca Irinel Catrina

Copyright (C) 2014 Signy Bendiksen et al. This is an open access article distributed under the Creative Commons Attribution License, which permits unrestricted use, distribution, and reproduction in any medium, provided the original work is properly cited.

\begin{abstract}
The etiology of viruses in osteoarthritis remains controversial because the prevalence of viral nucleic acid sequences in peripheral blood or synovial fluid from osteoarthritis patients and that in healthy control subjects are similar. Until now the presence of virus has not been analyzed in cartilage. We screened cartilage and chondrocytes from advanced and non-/early osteoarthritis patients for parvovirus B19, herpes simplex virus-1, Epstein Barr virus, cytomegalovirus, human herpes virus-6, hepatitis $\mathrm{C}$ virus, and human endogenous retroviruses transcripts. Endogenous retroviruses transcripts, but none of the other viruses, were detected in 15 out the 17 patients. Sequencing identified the virus as HERV-WE1 and E2. HERV-W activity was confirmed by high expression levels of syncytin, dsRNA, virus budding, and the presence of virus-like particles in all advanced osteoarthritis cartilages examined. Low levels of HERV-WE1, but not E2 envelope RNA, were observed in 3 out of 8 non-/early osteoarthritis patients, while only 3 out of 7 chondrocytes cultures displayed low levels of syncytin, and just one was positive for virus-like particles. This study demonstrates for the first time activation of HERV-W in cartilage of osteoarthritis patients; however, a causative role for HERV-W in development or deterioration of the disease remains to be proven.
\end{abstract}

\section{Background}

Osteoarthritis (OA) is one of the most common and painful forms of arthritis striking people worldwide and may affect all articular joints in the human body; however, it is most prevalent in hands, knees, hips, and spines [1]. The disease is commonly defined as a heterogeneous group of conditions that lead to joint pain and malfunction and is characterized by the progressive destruction of articular cartilage in addition to related changes in the subchondral bone and joint margins. Despite being one of the oldest documented diseases (arthritis has been demonstrated in ice-aged skeletons and dinosaur bones $[2,3]$ ), the exact etiology of this disease remains unknown. "Wear and tear" was in earlier days recognized as the main reason for the disease. Today we know that many factors seem to play a causal role in OA, including hereditary predisposition, wrong alignment of limbs, mechanical overloading, chronic inflammation, stress, obesity, ageing, and hormones $[4,5]$. Viral infection has also been suggested to play a causative role in the disease, but proof is lacking. Viral genomic sequences of the DNA viruses parvovirus B19, human herpes virus-1 (HHV-1; herpes simplex virus-1), HHV-3 (varicella zoster virus), HHV-4 (Epstein Barr virus), HHV-5 (human cytomegalovirus), transfusion transmission virus, and the RNA viruses $G B$ virus $C$ and endogenous retroviruses have 
been identified in OA patients [6-20]. However, other groups could not confirm these findings [21-28]. Moreover, viral nucleic acid sequences were detected in peripheral blood mononuclear cells, synovial fluid, or tissue, while cartilage or chondrocytes were not examined. Additionally, these viruses were also detected in non-OA control subjects $[6,8,9,11-$ 20]. These findings question the etiological role of viruses in osteoarthritis. To investigate the implication of viral infection in OA, we analyzed cartilage and chondrocytes obtained from advanced OA and non- or early OA patients for signs of active viral infection. For this purpose, we monitored specimens for viral genome sequences, expression of viral proteins, and virus particles. All samples were PCR or reverse-transcriptase PCR negative for parvovirus B19, HHV-1, HHV-3, HHV-5, HHV-6, and hepatitis C virus (HCV) with the exception of human endogenous retrovirus (HERV) which was common in cartilage from advanced OA patients, but not from nonOA and early OA patients. Partial sequencing identified this virus as HERV-W. Viral activity was evident by the presence of dsRNA, viral protein syncytin-1, and virus budding, and virus particles with estimated size corresponding to retroviruses could be visualized in the material of all OA patients tested. With the exception of one, samples of all non-OA and early OA patients did not show signs of viral particles. These findings suggest that activation of the endogenous retrovirus HERV-W is more common in OA patients than in controls, but it remains to be proven if this virus is implicated in the initiation/onset or progression of the disease.

\section{Methods}

2.1. Patients. Material from a total of 33 advanced $\mathrm{OA}$ patients (age 30-82) and 8 early or non-OA patients (age 2545) has been included in different parts of these experiments (donor list is summarized in Supplementary Table, in Supplementary Material available online at http://dx.doi.org/ 10.1155/2014/698609). All participants signed a written informed consent to use biopsies for scientific purposes. The project was approved by the Regional Ethic Committee (REK 61/2007 and 5.2006.161) and experiments were performed in accordance with the Code of Ethics of the World Medical Association (Declaration of Helsinki) for experiments involving humans. The patients involved in this study had incipient to severe osteoarthritis and were classified as grades 0-4 according to the Kellgren-Lawrence (KL) radiological classification of OA. Material analyzed in this study consisted of cartilage tissue and cells derived from patients with advanced osteoarthritis undergoing total joint replacement, and surplus chondrocytes expanded in monolayer cultures from patients with focal cartilage damages, undergoing autologous cell transplantation (autologous chondrocyte implantation (ACI); KL: 0-1). Additionally, healthy cartilage samples used in this study $(n=2)$ were taken from young adults suffering traumatic joint lesion (KL grade 0 ) in knee.

2.2. Cell Cultures. Cartilage biopsies were cut in small pieces and incubated with collagenase type XI and deoxyribonuclease type I and IV from bovine (Sigma-Aldrich, Germany) at $37^{\circ} \mathrm{C}$ for up to 15 hours. Collagenase-digested tissue was filtrated and spun down to eliminate excess of enzymes. Isolated chondrocytes were washed in PBS and cultured in complete medium, DMEM-F12 (Sigma-Aldrich) supplied with gentamicin (Sigma-Aldrich) and 10\% bovine serum (Sigma-Aldrich). Cells from ACI operations were expanded initially in $10 \%$ autologous serum to meet the requirements for transplantation in the clinics. Thereafter, surplus cells were transported to the lab and their expansion continued under the abovementioned conditions. Cells were grown to $80 \%$ confluence before each subculturing. Chondrocytes from both advanced OA and non-OA were expanded for 3-4 weeks ( 3 passages) before experimental analyses.

2.3. RNA-Isolating and cDNA Synthesis. Medium was removed and cells were washed in PBS; then PBS was removed and the cell pellet was quickly frozen at $-2^{\circ} \mathrm{C}$, ready for RNAisolating or resolved in freezing medium (medium with $20 \%$ bovine serum and 10\% DMSO (Sigma-Aldrich)). Cells were thawed and total RNA was prepared using Qiagen RNeasy Mini Kit (cat. number 74106). The RNA concentrations were measured by NanoDrop ND 1000 Spectrophotometer (Thermo Scientific, Wilmington, DE, USA). Then cDNA was synthesized using Oligo(dT) Primers (Amersham Pharmacia Biotec Inc.) and MonsterScript reverse transcriptase (Epicentre Biotechnologies, Madison, WI, USA) according to the manufactures' protocol.

2.4. Polymerase Chain Reaction (PCR). PCR was performed on cDNA using Phusion High Fidelity DNA polymerase (Finnzymes) and specific primers (Medprobe), listed in Table 1. All PCRs were performed on a PTC-200 Peltier Thermal Cycler; initiated melting; 5 minute, $96^{\circ} \mathrm{C}$, followed by 40 cycles with melting temperature $96^{\circ} \mathrm{C}$, annealing temperature $58^{\circ} \mathrm{C}$, and extension temperature $72^{\circ} \mathrm{C}$, all in 30-second intervals, and followed by final extension for 7 minutes at $72^{\circ} \mathrm{C}$. The PCR products were applied to an agarose gel before running electrophoresis. DNA band was visualized by UV light and photographed.

2.5. Immunocytochemistry. Cells were grown in medium DMEM-F12 supplied with gentamicin and 10\% FBS on camber slides (cat. number 177429, Nunc, Roskilde, Denmark) and starved $24 \mathrm{~h}$ in serum-free medium and then washed in cold PBS before incubating for 15 minutes with $0.5 \%$ saponin (Sigma-Aldrich; cat. number 47036-50G-F) for permeability and then for $2 \mathrm{~h}$ in cold PBS containing $2 \%$ sucrose and $4 \%$ paraformaldehyde. The cells were washed twice in cold PBS supplied with 1\% BSA. Anti-dsRNA-specific J2-IgG2A monoclonal antibody (English \& Scientific Consulting, Hungary) was diluted 1:100 in PBS added and incubated over night at $4^{\circ} \mathrm{C}$. Negative controls were performed by omitting primary antibody in this procedure. The cells were rinsed in PBS before adding Alexa Fluor stained IgG F(ab)2 fragment (Invitrogen) diluted 1: 400 in PBS supplied with $0.5 \% \mathrm{BSA}$ as secondary antibody and incubated over night at $4^{\circ} \mathrm{C}$ or for 2 hours at room temperature in dark. Labeled cell cultures were examined by fluorescence microscopy. 
TABLE 1: Virus-specific primers used in this study.

\begin{tabular}{|c|c|c|c|}
\hline Virus & GenBank acc. number & Primer sequences & Position \\
\hline \multicolumn{4}{|l|}{ HERVWE1 } \\
\hline \multirow{2}{*}{ Envelope (=syncytin) } & \multirow{2}{*}{ NM_014590 } & F: cat cga tag cac cca tca gat $g$ & $13-34$ \\
\hline & & R: gag tga aat agc atg aaa aca g & $3025-3004$ \\
\hline \multirow{2}{*}{ ERVWE1 gag } & \multirow{2}{*}{ AF156961 } & F: tgt ccg ctg tgc tcc tga tc & $1-20$ \\
\hline & & R: ctg cgc cag tgt cca gga gac & 1921-1901 \\
\hline \multicolumn{4}{|l|}{ HERVWE2 } \\
\hline \multirow{2}{*}{ Envelope } & AF127228, & F: cca ata gcc aga cca tta tat ac & $1-23$ \\
\hline & AF128229, & $\mathrm{R}:$ tgg ggt tcc att tgt aag acc & $1932-1912$ \\
\hline \multirow{2}{*}{ ERVWE2 gag } & \multirow{2}{*}{ AF123881 } & F: cta gaa cgt att ctg gag aat tg & $2-24$ \\
\hline & & R: ggc tct caa tgg tca aac ata $c$ & $1509-1488$ \\
\hline \multirow{2}{*}{ HHV-1 } & \multirow{2}{*}{ GU734772 } & F: tcc cca taa act ggg agt agc & $55192-55212$ \\
\hline & & R: cag aac tac agc gag ggc atc & $55327-55307$ \\
\hline \multirow{2}{*}{ HHV-6 } & \multirow{2}{*}{ NC_000898 } & F: gag tcc atg agt tag aag att & $150874-150894$ \\
\hline & & $\mathrm{R}$ : cta aat ttt cta cct ccg aaa tgt & 152099-152076 \\
\hline \multirow{6}{*}{ HHV-4 (Epstein Barr) } & \multirow{6}{*}{ V01555 } & External primers & \\
\hline & & F: agg gat gcc tgg aca caa ga & $48810-48829$ \\
\hline & & $\mathrm{R}: \operatorname{tgg} \operatorname{tgc} \operatorname{tgc}$ tgg tgg tgg caa $\mathrm{t}$ & $49406-49385$ \\
\hline & & Nested primers & \\
\hline & & F: tcttgatag gga tcc gct agg ata & $48839-48862$ \\
\hline & & $\mathrm{R}:$ acc gtg gttbctg gac tat ctg gat & $49335-49311$ \\
\hline \multirow{6}{*}{ HHV-5 (human cytomegalovirus) } & \multirow{6}{*}{ GQ222016 } & External primers & \\
\hline & & F: cag cac cat cct cct ctt cct ctg & $3665-3688$ \\
\hline & & R: cca agc ggc ctc tga taa cca agc & $4099-4076$ \\
\hline & & Nested primers & \\
\hline & & F: aga cac tgg ctc aga cct gac & $3708-3728$ \\
\hline & & R: aga gtc tgc tct cct agt gtg & 3989-3969 \\
\hline \multirow{6}{*}{ Hepatitis $C$ virus } & \multirow{6}{*}{ AB691598 } & External primers & \\
\hline & & F: ggc gac act cca cca tgg atc ac & $16-38$ \\
\hline & & R: cat gtt gca cgg tct acg aga cc & $342-320$ \\
\hline & & Nested primers & \\
\hline & & F: ctg tga gga act tct gtc tt & $43-62$ \\
\hline & & R: ctc gca agc acc cta tca gg & $309-290$ \\
\hline \multirow{5}{*}{ Human parvovirus B19 } & \multirow{5}{*}{ NC_000883 } & External primers & \\
\hline & & F: aat aca ctg tgg ttt tat ggg ccg & $1579-1602$ \\
\hline & & R: cca ttg ctg gtt ata acc aca ggt & $1862-1839$ \\
\hline & & $\begin{array}{l}\text { Nested primers } \\
\text { F: aat gaa aac } \mathrm{ttt} c \mathrm{ca} \mathrm{ttt} \text { aat gat gta } \mathrm{g}\end{array}$ & $1678-1705$ \\
\hline & & $\mathrm{R}: \mathrm{cta}$ aaa tgg ctt ttg cag ctt cta c & $1780-1756$ \\
\hline \multirow{6}{*}{ Rabbit endogenous retrovirus (HRV5) } & \multirow{6}{*}{ AF480924 } & External primers & \\
\hline & & F: tca ggt gct tca ttg gca gga tca & $3008-3031$ \\
\hline & & $\mathrm{R}:$ taa aat $\mathrm{ttg}$ tac $\mathrm{ttt}$ tgg gca ctg ctg & $3805-3782$ \\
\hline & & Nested primers & \\
\hline & & F: tgc aac ctt atg tta gtg cac tcc & $3052-3075$ \\
\hline & & $\mathrm{R}:$ tac tgc ctg gtc aac ata tag & $3766-3746$ \\
\hline
\end{tabular}

2.6. Transmission Electron Microscopy (TEM). Biopsies from patients were cut in small pieces $\left(1-2 \mathrm{~mm}^{3}\right)$ and fixed in McDowell's fixative as previously described [29]. Supernatants collected from collagenase XI-treated cartilages for breaking down matrix proteins were ultracentrifuged for 2 hours to isolate chondrocytes. The small pellets were resuspended in $100 \mu \mathrm{L}$ PBS and subjected to standard procedures for negative staining by uranyl acetate and microscopy.
2.7. Immune Electron Microscopy (IEM). Cartilage biopsies were cut in small pieces and fixed in $8 \%$ formaldehyde in PBS according to standard procedures [30, 31]. The presence of double-stranded RNA (dsRNA) was demonstrated using mouse anti-dsRNA J2-IgG2A monoclonal antibody (English \& Scientific Consulting, Hungary), diluted 1:50 in PBS supplemented with $1 \%$ cold water fish skin gelatin (G-7765; Sigma-Aldrich, St. Louis, MO) to block for nonspecific 
binding of antibodies. A second rabbit anti-mouse IgG antibody (ICN/Chappel, Aurora, $\mathrm{OH}$ ) was added, and binding was visualized by protein-A gold (University of Utrecht, The Netherlands). Between each step the specimens were washed in PBS supplied with cold fish skin gelatin. Finally, the grids were washed in distilled water and dried in $1.8 \%$ methylcellulose and $0.3 \%$ uranyl acetate and examined in a Jeol 1010 Transmission Electron Microscope (Tokyo, Japan).

\section{Results}

3.1. Identification of Endogenous Retroviral Transcripts in $O A$ Cartilage and Cultured Chondrocytes. Viral infections, including parvovirus B19, HHV-1, HHV-3, HHV-5, HERVs, and HCV, have been suggested as a causative factor in OA, but solid proof is lacking $[6,8,9,11-20]$. In fact, studies examining chondrocytes or cartilage of OA patients for the presence of virus are lacking and most studies have only examined the presence of viral genomes, rather than active viral infections. Because several viruses reside in a latent or persistent state in most individuals, the presence of viral mRNA was monitored as a sign of viral activity. Complementary DNA (cDNA) was prepared from RNA isolated from chondrocytes of collagenase-treated cartilage, nitrogencrushed cartilage, or 3rd passage chondrocyte cultures from OA patients and subjected to PCR using specific primers (Table 1). No PCR products were obtained with primers against parvovirus B19, HHV-1, HHV-4, HHV-5, HHV-6, and HCV (data not shown). In 1999, Griffiths and colleagues detected human retrovirus-5 (HRV-5), a virus later characterized as a rabbit endogenous retrovirus [10, 32]. Using primers complementary to sequences in the $\mathrm{pro} / \mathrm{pol}$ genes of HRV-5, multiple bands of approximately 200, 300, 700, and $1,000 \mathrm{bp}$ were obtained with cartilage tissue and cultureexpanded chondrocytes from all OA specimens $(n=17)$. A representative result for OA patients $2,8,9$, and 10 is shown in Figure 1. The presence of contaminating chromosomal DNA containing integrated endogenous retroviral DNA is unlikely because the isolated RNA was treated with DNase before being converted into complementary DNA (cDNA). Moreover, obtained cDNA was tested with primers against the adenine phosphoribosyltransferase (APRT) gene that generate a $300 \mathrm{bp}$ fragment for cDNA and an $800 \mathrm{bp}$ fragment for DNA. Only a $300 \mathrm{bp}$ fragment was obtained (results not shown). These findings underscore that the HERV amplicons were derived from transcripts and not from the chromosomal integrated viral genome.

3.2. Virus Identification: Sequencing of the Viral PCR Products. Nested PCR on the PCR reaction with inward HERV5 primers (Table 1) did not generate PCR products. We therefore sequenced of the PCR fragments obtained with the outward HERV-5 primers. Sequence analysis revealed that DNA was identical with human endogenous retrovirus W family. Mixed PCR on CDNA was repeated with specific primers for the ERVWE1 (ERVW-1; GenBank accession number NM_014590; [33]) and the ERVWE2 (GenBank accession numbers AF127228 and AF127229; [34]) envelope

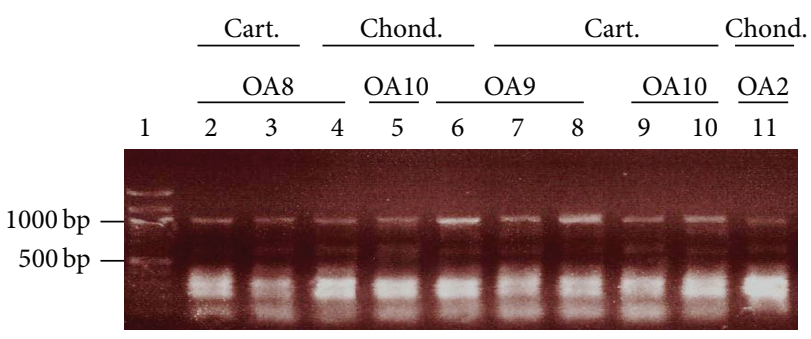

FIgURE 1: Detection of human endogenous retrovirus sequences in chondrocytes and cartilage from OA patients. Total RNA was isolated and converted into cDNA. HERV sequences were amplified using degenerated primers complementary to sequences in the pro/pol genes of HRV-5 (Table 1) to obtain a 1,000 bp fragment. Lane 1: DNA marker (in $\mathrm{kb}$ ); lanes 2-4: OA8; lanes 4, 8, and 10: OA10; lanes 6-8: OA9; lane 11: OA2. Lanes 2, 8, and 9: RNA isolated from nitrogen-crushed cartilage; lanes 3, 7, and 10: RNA obtained from enzyme-digested cartilage; lanes 4-6 and 11: RNA purified from culture-expanded chondrocytes. PCR reactions were run on an agarose gel, stained with ethidium bromide, and the DNA was visualized under UV light. Cart.: cartilage; chond.: chondrocytes.

TABLE 2: PCR results using HERV degenerated and ERVWE1- and ERVW2-specific primers.

\begin{tabular}{lcccc}
\hline $\begin{array}{l}\text { Patient } \\
\text { group }\end{array}$ & $\begin{array}{c}\text { ERVWE1 } \\
\text { env } \\
(3000 \mathrm{bp})\end{array}$ & $\begin{array}{c}\text { ERVWE2 } \\
\text { env } \\
(1600 \mathrm{bp})\end{array}$ & $\begin{array}{c}\text { ERVWE1 } \\
\text { gag } \\
(1900 \mathrm{bp})\end{array}$ & $\begin{array}{c}\text { ERVWE2 } \\
\text { gag } \\
(1500 \mathrm{bp})\end{array}$ \\
\hline OA & $15 / 17(88 \%)$ & $15 / 17(88 \%)$ & $5 / 6(83 \%)$ & $5 / 6(83 \%)$ \\
$\begin{array}{l}\text { Non-/early } \\
\text { OA }\end{array}$ & $3 / 8(38 \%)$ & $0 / 8(0 \%)$ & $\mathrm{NT}^{*}$ & $\mathrm{NT}$ \\
\hline
\end{tabular}

${ }^{*} \mathrm{NT}$ : not tested.

genes (env; also referred to as syncytin). Two distinct PCR products of, respectively, $\sim 3,000$ and $\sim 1,900$ bp were detected in cartilage specimens of 15 out of $17 \mathrm{OA}$ patients, but not in one non-OA patient (Figures 2(a) and 2(b); Table 2). The length of PCR products corresponds well with the theoretical length of $3013 \mathrm{bp}$ and $1932 \mathrm{bp}$, respectively. Partial sequencing of the 3,000 bp PCR products confirmed that the amplified fragment spans a region of the envelope (env) gene encoding syncytin of the ERVW member E1 (ERVWE1; Supplementary Figure S1 $[33,35])$, while the sequence data of the $\sim 1,900$ bp fragment showed $>95 \%$ identity with the env gene of ERVWE2 (Figure 3). The viral sequences detected in our OA patients possessed point mutations compared to the reference strains ERVWE1 and ERVWE2, respectively, arguing against contamination of the samples (Figure 3 and Supplementary Figure S1). To confirm the presence of ERVW-specific transcripts in material from OA patients, PCR was performed on cDNA prepared from expanded chondrocytes from 6 OA patients (OA3, OA7, OA8, OA9, OA10, and OA48) using another primer set specific for the ERVWE1 and ERVWE2 gag gene ([GenBank: AF156961 and AF123881], resp.; [34, 36]). ERVWE1 and ERVWE2 gag PCR amplicons corresponding to the expected $1920 \mathrm{bp}$ and $1508 \mathrm{bp}$, respectively, could be detected in the chondrocytes of all patients tested, except OA3 which had only ERVWE1 gag transcripts and OA48 which had only ERVWE2 gag 


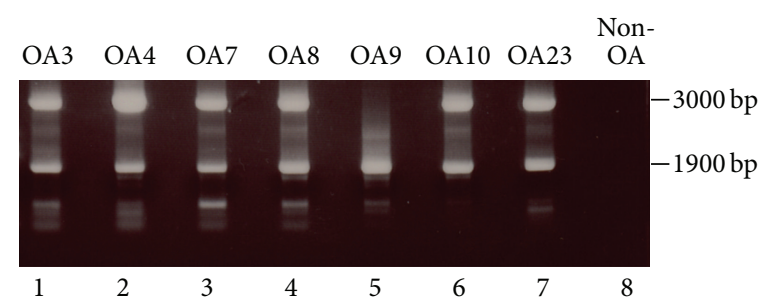

(a)

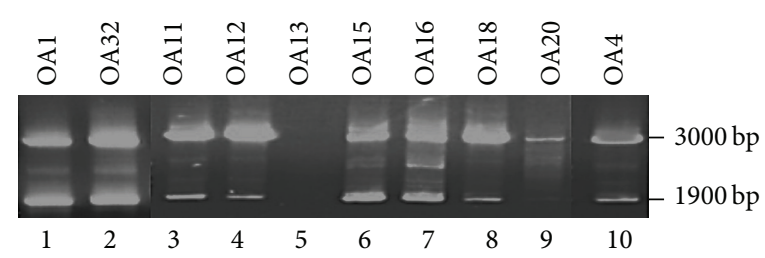

(b)

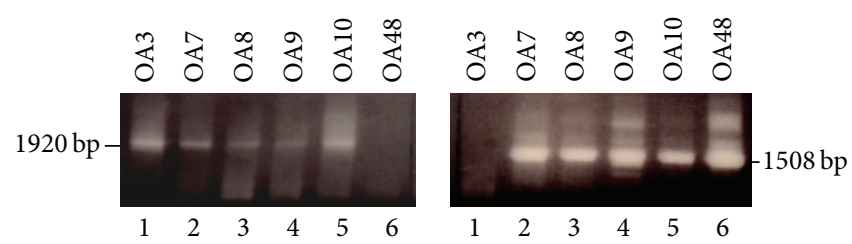

(c)

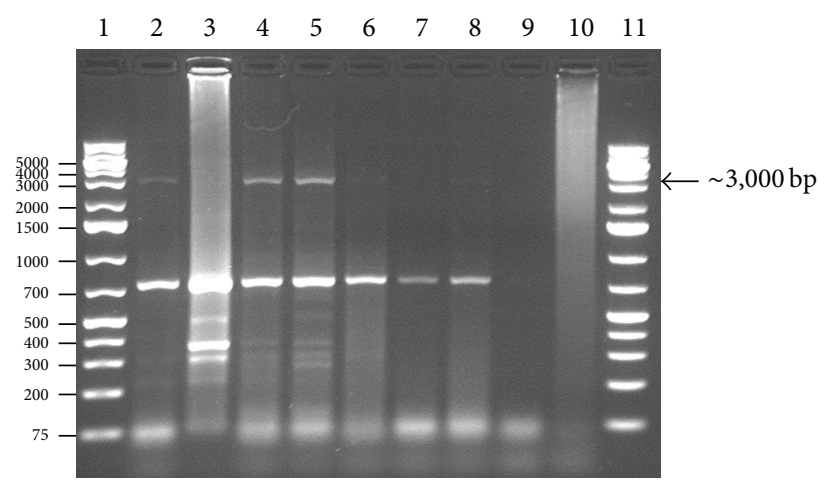

(d)

FIGURE 2: Expression of ERVWE1 and ERVW2 in chondrocytes from OA and non- or early OA patients. (a) PCR on cDNA prepared from cultured chondrocytes isolated from knees or hip from OA patients. Specific primers for the ERVWE1 and ERVWE2 env gene (encoding syncytin) were used. (b) RNA purified from nitrogen-crushed cartilage. (c) RNA was isolated from chondrocytes obtained from 6 OA patients, converted into cDNA, and amplified using specific primers complementary to the gag gene of HERVWE1 (left panel) and HERVWE2 (right panel) sequences. (d) Amplification of cDNA prepared from chondrocytes from non- and early OA patients. Lanes 1 and 11: $1 \mathrm{~kb}$ plus ladder; lanes 2-10: amplified cDNA. The arrow indicates the presence of the amplified 3,000 bp of the ERVWE1 env transcript.

transcripts (Figure 2(c)). No env-specific transcripts were detected in the chondrocytes from the non-OA patient (Figure 2(a)), but because only one non-OA patient was originally included, we expanded our control group with patients with only focal cartilage damage. We tested cDNA prepared from RNA isolated from chondrocytes from eight non-/early OA patients for the presence of ERVWE gag sequences. Weak PCR signals corresponding to the $\sim 3,000 \mathrm{bp}$ fragment were detected for 3 of these 8 patients (Figure 2(d), lanes 2, 4, and 5), while none of them were positive for the $1,600 \mathrm{bp}$ fragment (Figure 2). These results suggest that ERVWE1, but not ERVWE2, may be expressed in some of the non-/early OA patients.
3.3. Detection of Viral dsRNA and the Viral Envelope Protein Syncytin-1. Retroviruses pack their two copies of their genomes as dimers, and viral dsRNA can be purified from cells infected with retroviruses. Moreover, the viral genome can form long hairpin ds RNA region, for example, with its tRNA primer [37-43]. We reasoned that activation of ERVWE in chondrocytes would result in the presence of viral dsRNA. We therefore examined chondrocytes from $\mathrm{OA}$ and non- or early OA patients for the presence of dsRNA intermediates with an antibody that specifically recognizes longer stretches of dsRNA. This antibody will react with viral dsRNA, but not with cellular dsRNA [44, 45]. In immunofluorescence (IF) assays, chondrocytes prepared 


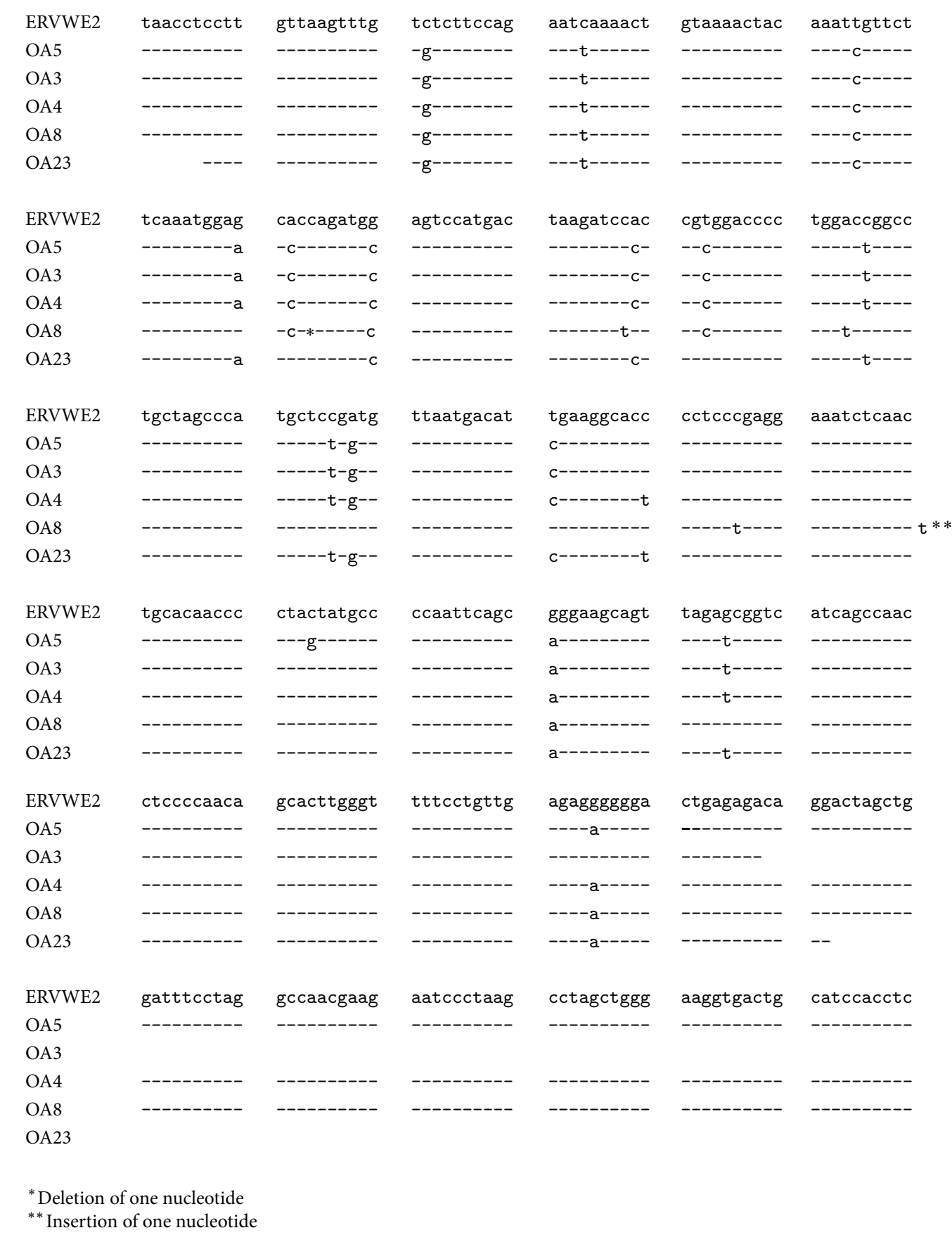

FIGURE 3: Alignment of the sequence of the 1,600 bp PCR products with ERVWE2 env transcript. Identical nucleotides are indicated by a vertical line, while point mutations are shown. The sequence obtained from OA8 patient has a deletion and insertion which restores the ORF.

from OA cartilage samples showed a strong immunoreaction for dsRNA at both the cytoplasmic and the nuclear regions (Figure 4(a)). Additionally, traces of cytoplasmic nucleic acids could be observed in cells by DAPI staining, most likely corresponding to viral dsRNA. Chondrocytes prepared from autologous chondrocyte implantation (ACI) operations displayed no or very low (e.g., patient 3 in Figure 4(b)) staining with dsRNA-specific antibodies (Figure 4(b); Table 2). The detection of dsRNA underscores the possible presence of endogenous retrovirus, but we cannot exclude the fact that these antibodies recognize other dsRNA from other sources like RNA interference molecules or other viruses (e.g., dsRNA reoviruses). However, cartilage forms a closed system with no supply of blood and lymph and no nerves so that the presence of exogenous viruses can be excluded. Because material from non-OA had no or weak dsRNA staining, it seems unlikely that the signals in OA material derive from the RNA interference pathway. To certify HERV-W activity, 

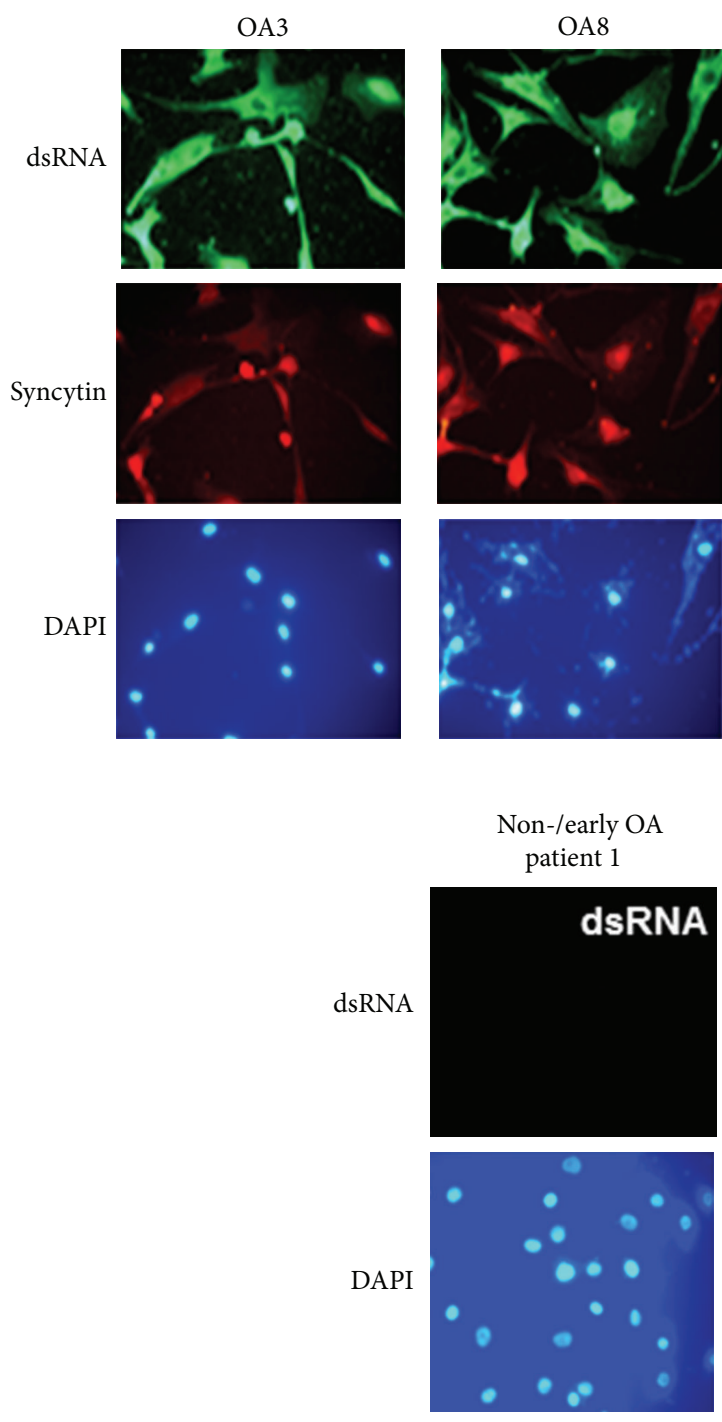

OA8
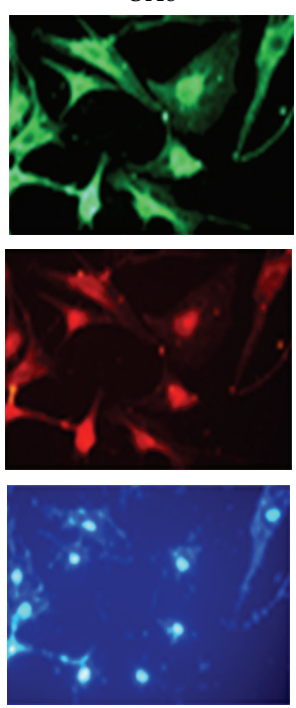

Non-/early OA

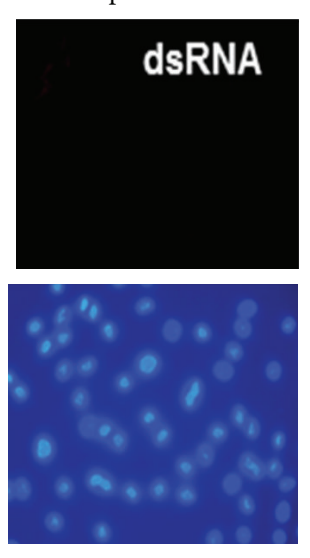

(b)

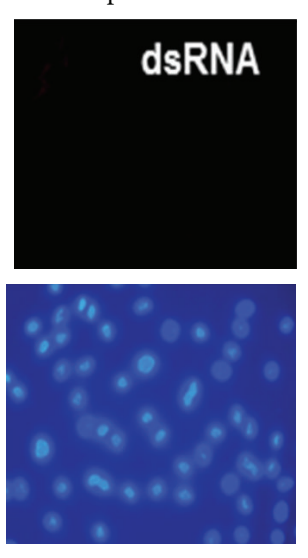

OA23
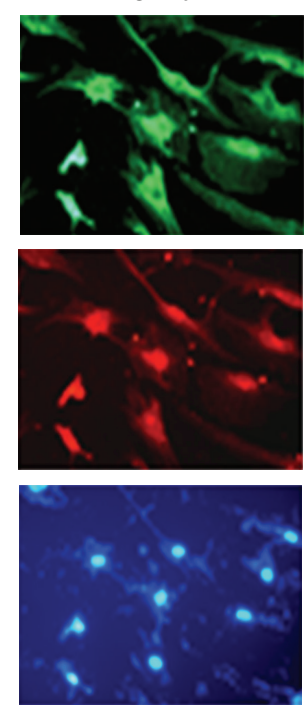

(a)

Non-/early OA patient 2
OA20
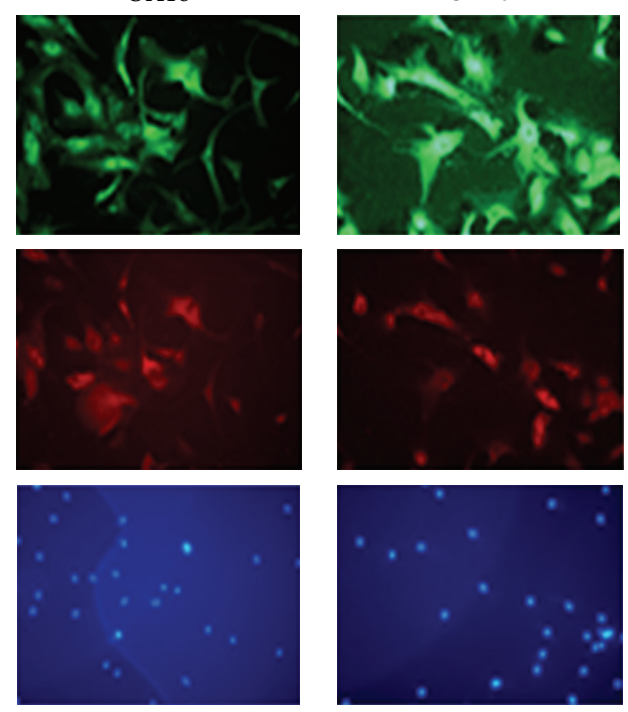

Non-/early OA patient 3
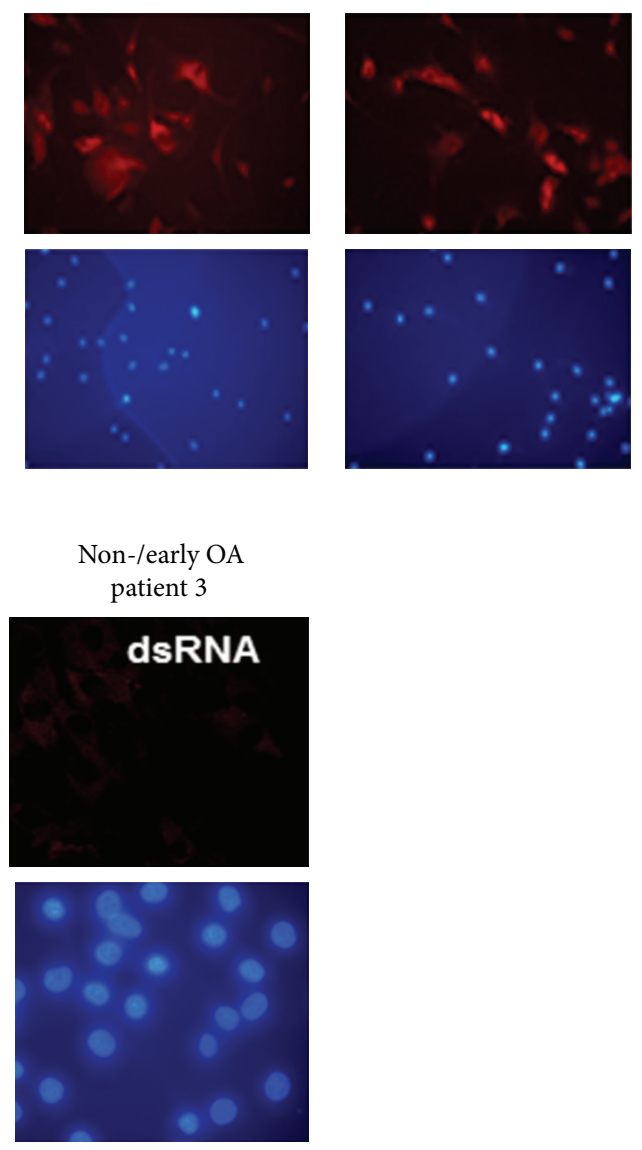
FIGURE 4: Presence of dsRNA and syncytin-1 in chondrocyte cultures obtained from OA and non- or early OA patients. Immunofluorescence
assay with specific antibodies against dsRNA and syncytin was used. (a) Top row: chondrocytes from OA patients were examined for the presence of viral dsRNA by immunofluorescence using antibodies that specifically react with viral dsRNA. Middle row shows the expression of syncytin-1 in chondrocytes of the same OA patients. Bottom row: DAPI staining shows strong nuclear staining and weak cytoplasmic staining for nucleic acids. (b) Chondrocyte cultures from non-/early OA patients were monitored for the presence of dsRNA (top panel). Notice weak staining for dsRNA in chondrocytes from patient 3. Bottom row: DAPI staining.

samples were analyzed for expression of the envelope protein syncytin-1. Immunofluorescence showed abundant expression of syncytin-1 in OA-derived chondrocytes distributed all over the cell, while no or low syncytin-1 staining was observed in samples from non-/early OA patients (Figure 4(a); Table 3). Of the 22 OA patients examined, 20 expressed dsRNA and syncytin in their chondrocytes (Table 3 ). In parallel experiments, OA cartilage specimens and cells were examined by cryoimmuno-EM with the same antibodies. This procedure revealed expression of dsRNA in small clusters distributed across the cytoplasm and the nucleus (Figure 5(a), panels A and B). Interestingly, at the ultrastructural level we observed that both dsRNA and syncytin colocalized in the same clusters, scattered throughout the cytoplasm and nucleus (Figure 5(a), panel C). Of note, expression of dsRNA was not restricted to advanced $\mathrm{OA}$ cases since immunolabeling was achieved in cells from ACI and non-OA patients (Figure 5(b), panels $B$ and $C$, and Table 3). Chondrocyte lysates from OA patients displayed immunoreactivity against syncytinspecific antibodies, suggesting the presence of syncytin in these cells (Figure 5(c)).

3.4. Viral Budding and Virus-Like Particles. HERV genomes are integrated in the cellular chromosomes but most of these retroviral genomes are transcriptional silenced due to mutations in their coding regions or DNA methylation 
TABLE 3: Prevalence of dsRNA, syncytin-1, and HERV-like particles in samples from OA and non-/early OA patients.

\begin{tabular}{|c|c|c|c|c|c|c|}
\hline Material/method & IF syncytin & IF dsRNA & IEM syncytin & IEM dsRNA & TEM VLP & TEM budding \\
\hline Chondrocytes OA & $20 / 22^{*}(\mathrm{~S})^{* *}$ & $20 / 22(S)$ & $7 / 7(\mathrm{~S})$ & $7 / 7(S)$ & $6 / 7$ & $5 / 7$ \\
\hline Cartilage OA & & & $7 / 7(S)$ & $7 / 7(S)$ & $22 / 24$ & $16 / 24$ \\
\hline Chondrocytes non-OA & $4 / 7(3 \mathrm{~W}, 1 \mathrm{~S})$ & $3 / 7(2 \mathrm{~W}, 1 \mathrm{~S})$ & $4 / 7(3 \mathrm{~W}, 1 \mathrm{~S})$ & $3 / 7(2 \mathrm{~W}, 1 \mathrm{~S})$ & & $1 / 8$ \\
\hline Cartilage non-OA & & & $3 / 5(2 \mathrm{~W}, 1 \mathrm{~S})$ & $3 / 5(2 \mathrm{~W}, 1 \mathrm{~S})$ & & \\
\hline Collagenase-treated supernatants OA & & & & & $3 / 4$ & \\
\hline
\end{tabular}

${ }^{*}$ Number of positive samples/total number of samples.

${ }^{* *}$ S: strong staining; W: weak staining; VLP: virus-like particles.

[46-48]. However, some HERVs can encode retroviral proteins and viral particles have been isolated [48-51]. The detection of the retroviral syncytin protein in chondrocytes and cartilage samples from $\mathrm{OA}$ patients prompted us to look for retrovirus particles. EM pictures taken from OA cartilage specimens showed virus-like particles holding an envelope-like structure with an estimated size of $100 \mathrm{~nm}$ (Figure 6), which corresponds to the size of human endogenous retrovirus particles [52-55]. Importantly, virus-like particles showed specific reactivity against syncytin-1 antibodies, as demonstrated by immune-EM gold labeling (Figure 6(d)). Similar virus-like particles also stained positively for the envelope protein syncytin in whole-mounted collagenasedigested OA-cartilage samples (Figure 6(c)). Last, we were also able to capture virus-budding processes from cell bodies in some specimens (Figure 6(a)). No retrovirus-like particles were observed in material of early or non-OA patients, except for one patient (Figure 5(b), panel C, insert). Because of the limited size of the specimens, there was not enough material to isolate and further characterize these virus particles.

\section{Discussion}

Viral infection has been suggested as an etiological factor in $\mathrm{OA}$, but unequivocal proof is lacking. While viral nucleic acids and antibodies have been demonstrated in blood and synovial fluids/tissues from OA patients, studies monitoring the presence of viral activity, either as transcripts, proteins, or viral particles, in cartilage or chondrocytes from such patients have not been reported, so that a causal role of viruses in this disease remains enigmatic $[6,8,12,16,18$, $23,24]$. The conclusion of a contributing role of viruses in OA has also been hampered by the absent or relatively few healthy, non-OA patients examined in comparative studies. To the best of our knowledge, only one study investigated the presence of viral mRNA in cartilage of OA patients. Rollin and coworkers found HHV-4 transcripts in cartilage in 2 out of 12 OA patients, but not in twelve healthy controls [18]. We examined cartilage and cultured chondrocytes obtained from advanced OA and early/non-OA patients for the presence of viral transcripts. We could not detect mRNA from parvovirus B19, different human herpes viruses, and hepatitis C virus. However, we could show the presence of HERV activity. Our results are the first to demonstrate that activation of the endogenous retroviruses ERVWE1 and
ERVWE2 occurs in cartilage/chondrocytes from OA patients and that this is a more common phenomenon in advanced than in early/non-OA patients. Activation of ERVWE1 and ERVWE2 was demonstrated here by the presence of dsRNA, ERVW-specific transcripts, expression of the viral protein syncytin, the occurrence of viral budding, and the presence of virus-like particles with morphology and size similar to the previously described MSRV and HERV-W $[31,56]$. Sequencing cDNA representing part of the viral env transcripts revealed the presence of mutations compared to the sequences deposited in GenBank. Moreover, sequences between patients contained different mutations. This argues against contamination of our material. Several groups had detected transcripts of HERV in material of OA patients, but cartilage and chondrocytes had not been examined so far. HERV-K mRNA was identified not only in peripheral blood mononuclear cells from 17 out of 17 OA patients $[19,20]$ but also in synovial fluid of 4/10 (resp., 10/10, 4/4, and 2/3) OA patients $[14,17]$. A recent study reported that $48 \%(54 / 113)$ of OA patients had detectable HERV-K18 expression in blood versus $36 \%(22 / 62)$ of healthy controls $(P=0.12)$, and there was an association between HERV-K18 expression and the OA severity index. These findings suggest that other HERVs may be implicated in OA [57]. Transcripts of the polymerase gene of HERV were detected in 3 out of 3 synovial samples from OA patients [7]. Other researchers have failed to identify HERV transcripts or retroviral particles in synovial fluid from OA patients [21, 22]. In 1999, the group of Venables reported the amplification of human retrovirus-5 (HRV-5) mRNA in synovial membranes from $3 / 5$ OA patients, but not from control individuals (0/13), while viral DNA could be detected in synovial membranes of OA patients (3/9) and one normal subject $(n=29)[9,10]$. This could not be confirmed in another study, where none of the synovial tissue samples from $75 \mathrm{OA}$ patients tested positive for HRV5 DNA [26]. Later on, it was shown that HRV-5 is not integrated in human DNA and that this virus belongs to an endogenous retrovirus family found in rabbits and should be renamed RERV-H [32]. Additional pitfalls that make the interpretation of the results ambiguous are that none of the studies actually screened for viral activity in chondrocytes and that samples of control subjects (non-OA) patients often displayed similar prevalence of HERV transcript. We readily detected dsRNA and syncytin-1 in chondrocytes in 20 out of 22 tested OA patients, while weak expression levels of dsRNA 


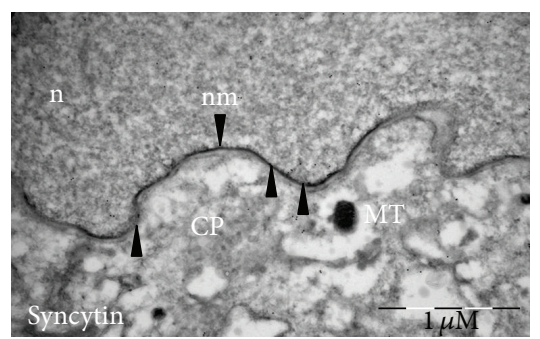

(A)

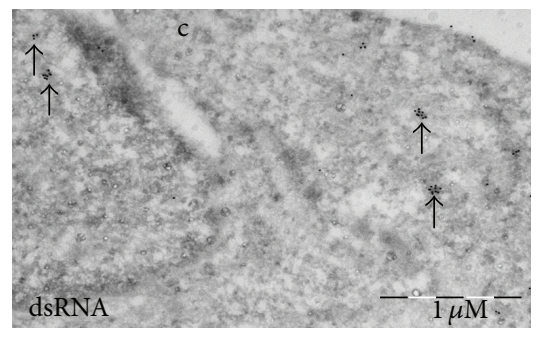

(B)

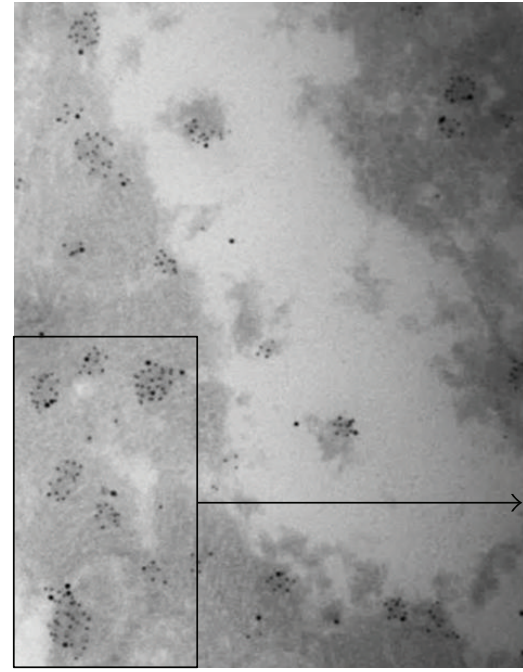

(C)

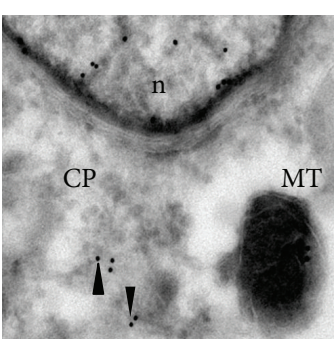

$\left(\mathrm{A}^{\prime}\right)$

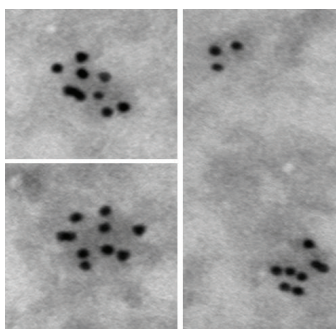

$\left(B^{\prime}\right)$

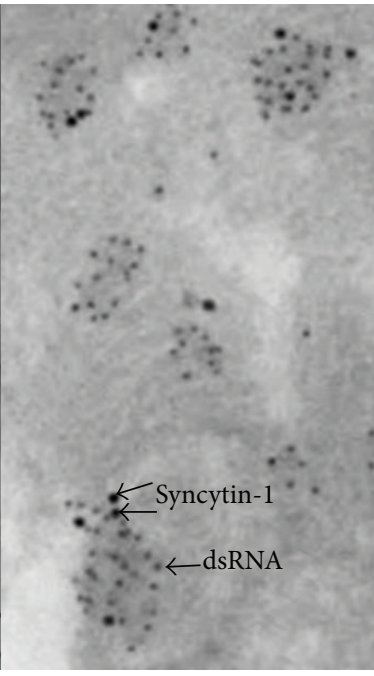

(a)

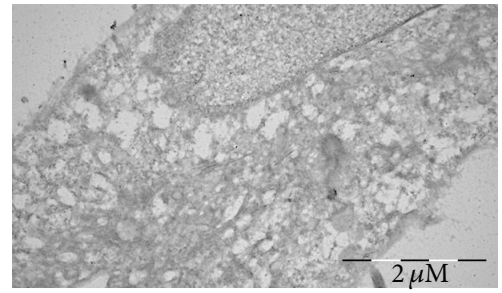

(A)

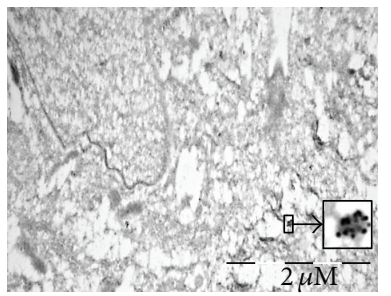

(B)

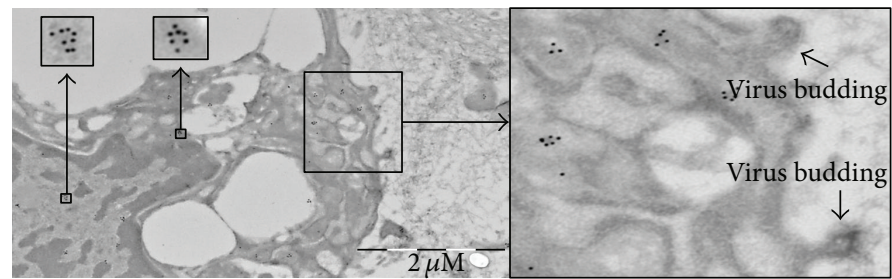

(C)

(b)

Figure 5: Continued. 


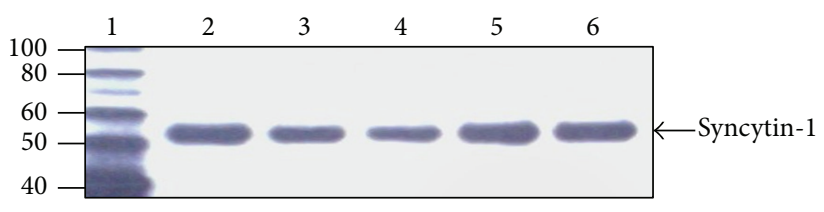

(c)

FIGURE 5: Detection of dsRNA and syncytin-1 in chondrocyte cultures obtained from OA patients by IEM. (a) IEM on samples from OA patients. Panels A and A': cryo-IEM shows the presence of syncytin in the nucleus and cytoplasm (arrow heads). CP: cytoplasm; CM: nuclear membrane; MT: mitochondrion; n: nucleus. Panels B and $\mathrm{B}^{\prime}$ : detection of dsRNA. Panel C illustrates that dsRNA (small dots) and syncytin (large dots) colocalize. (b) Cryo-IEM of virus dsRNA in early or non-OA patients (ACI). Panel A shows a completely negative sample and represents two out of five tested chondrocyte cultures. Panel B: example of very low levels of dsRNA detected in chondrocyte culture of a nonOA patient. Panel C: chondrocyte culture from one of the non-/early OA patients expressed relatively high levels of dsRNA. The insert depicts structures resembling virus budding (marked with an asterisk). (c) Western blot performed on lysates prepared from chondrocytes isolated from OA patients. The expression of syncytin-1 was monitored using syncytin-1 specific antibodies. A band of $\sim 55 \mathrm{kDa}$ which corresponds to the theoretic molecular mass of syncytin-1 is visible in all lysates. Lane 1: protein marker (in $\mathrm{kDa}$ ); lanes 2-6: chondrocyte lysates.

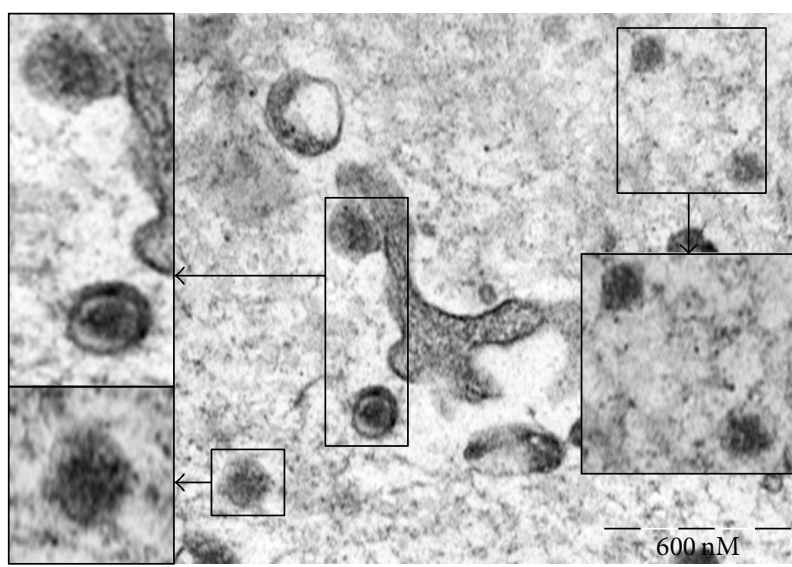

(a)

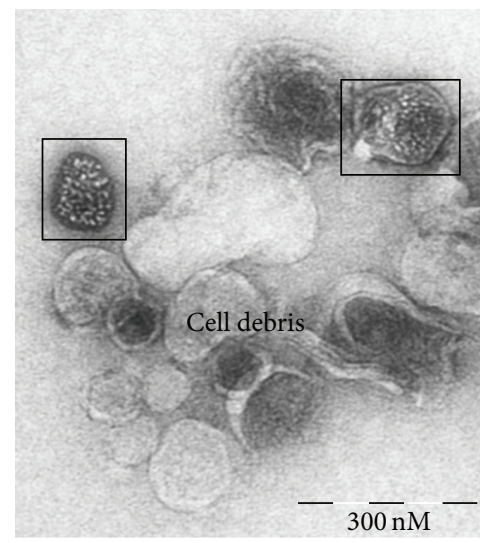

(c)

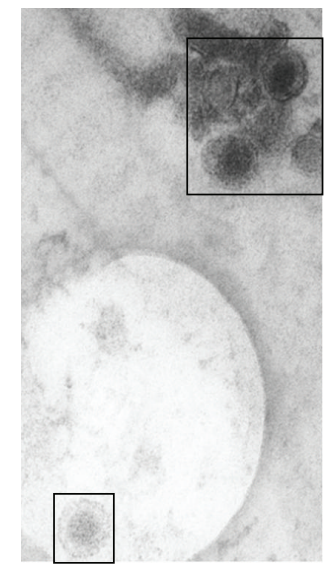

(b)

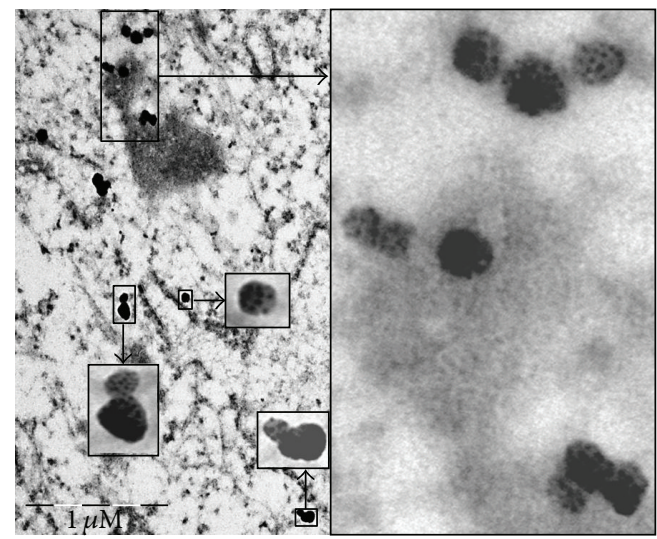

(d)

FIGURE 6: Retrovirus-like particles in cartilage of OA patients. Transmission EM ( $a, b$, and d) and negative staining EM (c) were used to monitor the presence of virus-like particles in cartilage samples from OA patients. Negative staining EM was performed on collagenasetreated cartilage, and the resulting subcellular bodies were absorbed into grids. (d) Immune-gold labeling of viruses with antibodies against envelope protein syncytin. The size bar is indicated.

and syncytin were detected in cells derived from 3 out of 7 non-OA patients that were examined. One patient (a young, healthy woman in her twenties with a sports injury, but with no sign of osteoarthritis) had high levels of both dsRNA and syncytin, and virus-like particles were present in cartilage from this patient. Although we did not use quantitative methods, fluorescence staining for dsRNA and syncytin-1 was visually weaker in non-OA patients compared to OA patients. 
We readily detected the presence of retrovirus-like particles in OA patients, but no such particles were observed in the cartilage biopsies taken from non-/early OA patients, except for one individual. We cannot rule out the fact that HERV particles were present in cartilage samples of chondrocytes from the other non-OA patients we examined because only a limited fraction of this material was examined. However the size of sample from non-/early OA patients was similar to that of OA patients. Our findings suggest that viral activation is at least more common in these patients compared to the control group. The observation that none of the chondrocytes isolated from non-/early OA patients $(n=8)$ possessed ERVWE2 transcripts, while 20 ERVWE2-specific transcripts were observed in 20/22 of the OA patients, may indicate that activation of this member of HERV is a hallmark for OA and can be used as a diagnostic marker.

The much higher incidence of ERVWE1/2 activation in OA patients compared to the control group may suggest that the disease status may trigger endogenous retroviral activation. Steroid hormones and inflammation are known risk factors for OA [58-63]. Interestingly, these conditions can also induce activation of HERV [64-67]. A drawback of our study is that relatively few non-OA patients were examined and their average age was significantly younger than the OA patients (range $25-45$ years versus $30-82$ years). For obvious reasons, it is difficult to obtain material from age-matched healthy individuals. Moreover, most samples are of very limited size making it impossible to test them by all techniques applied here in this study. The control group included younger patients suffering local cartilage damage or traumatic joint lesion (sport injuries). The increased prevalence of HERV-W in OA patients compared to the control group could therefore be age related. However, no age-related expression of HERV-W has been reported so far in other diseases where this virus has been found to be expressed. Indeed, significantly increased HERV-W pol transcript levels were monitored in cerebrospinal fluids from CreutzfeldtJakob disease patients compared to normal controls (86/87 versus 33/40; $P=0.001$ ), but no correlation with sex and age existed [68]. Similarly, no significant correlation emerged between the expression of HERV-W env gene and age in PBMC either from autistic spectrum disorder patients or from healthy individuals [69]. The lack of a correlation between HERV-W expression and age has been reported by other groups $[70,71]$. Therefore, it is unlikely that old age causes retroviral activation in cartilage of OA patients.

Assuming the implication of ERVW in the onset or progression of $\mathrm{OA}$, a pivotal question that must be solved is the mechanisms by which this retrovirus contributes to the cytotoxic processes in OA. Active viral replication may contribute to the sustained inflammation of the synovial tissue that is often seen in the context of OA $[59,61]$. We observe syncytin-1 expression in chondrocytes from OA patients and to a lesser extent in cells from some non-/early OA controls. Syncytin-1 is primarily produced by placental trophoblasts where it participates in cell-to-cell fusion [72, 73], but it can be expressed by some normal somatic cells. In diseased nonplacental tissue, malignant cells, as well in connection with different autoimmune diseases syncytin-1 expression has been also observed [74-79]. The role of syncytin-1 in cancer is incompletely understood, but it has been suggested to promote tumor-tumor and tumor-host cell fusion. Other groups propose a connection between syncytin expression and cell proliferation [80, 81]. Syncytin-1 has been shown to regulate inflammation in neural cells [82]. Thus, ectopic expression of syncytin-1 in human fetal astrocytes induces expression of the endoplasmic reticulum stress genes $B i P$ and $X B P-1 / s$, the proinflammatory cytokine interferon $\alpha$ gene, and the NOS2 gene. In addition, syncytin-1 provokes increase in intracellular $\mathrm{Ca}^{2+}$ levels and supernatants from cell expressing syncytin-1 caused cytotoxic effects on oligodendrocytes $[82,83]$. Intriguingly, $\mathrm{Ca}^{2+}$ has been shown to stimulate the activity of the enzymes matrix metalloproteases, phospholipase A2, and calmodulin-dependent kinase II, all of which may be important in the pathophysiology of OA [8487].

\section{Conclusions}

We have shown higher prevalence of ERVWE1 and ERVWE2 activity in chondrocytes and cartilage of OA patients compared to non-/early OA patients. However, we cannot conclude whether these viruses are innocent bystanders that are activated by pathological processes occurring during the development of $\mathrm{OA}$ or whether they are involved in the onset or the progression/deterioration of the disease. The high prevalence of activated ERVWEs, especially ERVWE2, may be an indicator of OA, making the detection of ERVWE transcripts a putative diagnostic marker.

\section{Abbreviations \\ ACI: Autologous chondrocyte implantation \\ bp: Base pairs \\ cDNA: Complementary DNA \\ dsRNA: Double-stranded RNA \\ EBV: $\quad$ Epstein Barr virus \\ HCV: Hepatitis $C$ virus \\ HERV: Human endogenous retrovirus \\ HHV: Human herpes virus \\ HSV: Herpes simplex virus \\ IEM: Immunoelectron microscopy \\ MSRV: Multiple sclerosis-associated retrovirus \\ OA: Osteoarthritis \\ ORF: Open reading frame \\ PCR: Polymerase chain reaction \\ RT-PCR: Reverse-transcriptase PCR \\ TEM: Transmission electron microscopy.}

\section{Conflict of Interests}

The authors declare that they have no conflict of interests.

\section{Authors' Contribution}

Signy Bendiksen, Conny Tümmler, Elisabeth Olsen, and Randi Olsen performed the experiments; Signy Bendiksen, 
Inigo Martinez-Zubiaurra, Gunnar Knutsen, Jan Elvenes, and Ugo Moens participated in the conception and design of the experiments; Signy Bendiksen, Conny Tümmler, Elisabeth Olsen, Randi Olsen, Gunnar Knutsen, Jan Elvenes, Inigo Martinez-Zubiaurra, and Ugo Moens analyzed and interpreted the data; Inigo Martinez-Zubiaurra, Gunnar Knutsen, and Jan Elvenes provided patient material; Signy Bendiksen, Inigo Martinez-Zubiaurra, and Ugo Moens wrote the first draft of the paper; Signy Bendiksen, Inigo MartinezZubiaurra, Ugo Moens, Gunnar Knutsen, and Jan Elvenes critically revised the paper. All authors read and approved the final paper.

\section{Acknowledgments}

This work was supported by grants provided by Sigval Bergesen d.y. and Hustru Nanki's Almennyttige Stiftelse, Agnes Sars Foundation, and Oslo Sanitetsforening. The authors thank Helga Marie Bye for excellent technical assistance.

\section{References}

[1] A. J. Hough Jr., "Pathology of osteoarthritis," in Arthritis and Allied Conditions, W. J. Koopman and L. W. Moreland, Eds., pp. 2169-2197, Lippincott Williams \& Wilkins, Philadelphia, Pa, USA, 2005.

[2] C. W. Bishop, C. G. Abbot, and A. Hrdlick, Man from the Farthest Past, vol. 7 of Smithsonian Scientific, Smithsonian Institution, New York, NY, USA, 1930.

[3] S. O. Waife, "Disease in ancient man," Journal of American Medical Association, vol. 253, no. 5, pp. 694-695, 1985.

[4] R. K. Chaganti and N. E. Lane, "Risk factors for incident osteoarthritis of the hip and knee," Current Reviews in Musculoskeletal Medicine, vol. 4, no. 3, pp. 99-104, 2011.

[5] L. J. Sandell, "Etiology of osteoarthritis: genetics and synovial joint development," Nature Reviews Rheumatology, vol. 8, no. 2, pp. 77-89, 2012.

[6] J. G. Saal, M. Steidle, H. Einsele, C. A. Muller, P. Fritz, and J. Zacher, "Persistence of B19 parvovirus in synovial membranes of patients with rheumatoid arthritis," Rheumatology International, vol. 12, no. 4, pp. 147-151, 1992.

[7] K. Nakagawa, V. Brusic, G. McColl, and L. C. Harrison, "Direct evidence for the expression of multiple endogenous retroviruses in the synovial compartment in rheumatoid arthritis," Arthritis and Rheumatism, vol. 40, no. 4, pp. 627-638, 1997.

[8] Y. Takahashi, C. Murai, S. Shibata et al., "Human parvovirus B19 as a causative agent for rheumatoid arthritis," Proceedings of the National Academy of Sciences of the United States of America, vol. 95, no. 14, pp. 8227-8232, 1998.

[9] A. Brand, D. J. Griffiths, C. Herve, E. Mallon, and P. J. W. Venables, "Human retrovirus-5 in rheumatic disease," Journal of Autoimmunity, vol. 13, no. 1, pp. 149-154, 1999.

[10] D. J. Griffiths, S. P. Cooke, C. Hervé et al., "Detection of human retrovirus 5 in patients with arthritis and systemic lupus erythematosus," Arthrithis \& Rheumatism, vol. 42, no. 3, pp. 448-454, 1999.

[11] C. A. Seemayer, S. Viazov, M. Neidhart et al., "Prevalence of TTV DNA and GBV-C RNA in patients with systemic sclerosis, rheumatoid arthritis, and osteoarthritis does not differ from that in healthy blood donors," Annals of the Rheumatic Diseases, vol. 60 , no. 8, pp. 806-809, 2001.
[12] D. Peterlana, A. Puccetti, R. Beri et al., "The presence of Parvovirus B19 VP and NS1 genes in the synovium is not correlated with rheumatoid arthritis," The Journal of Rheumatology, vol. 30, no. 9, pp. 1907-1910, 2003.

[13] C. Lennerz, H. Madry, S. Ehlhardt, T. Venzke, K. D. Zang, and Y. Mehraein, "Parvovirus B19-related chronic monoarthritis: Immunohistochemical detection of virus-positive lymphocytes within the synovial tissue compartment: two reported cases," Clinical Rheumatology, vol. 23, no. 1, pp. 59-62, 2004.

[14] S. Ehlhardt, M. Seifert, J. Schneider, A. Ojak, K. D. Zang, and Y. Mehraein, "Human endogenous retrovirus HERV-K(HML2) Rec expression and transcriptional activities in normal and rheumatoid arthritis synovia," The Journal of Rheumatology, vol. 33, no. 1, pp. 16-23, 2006.

[15] R. Rollín, R. Álvarez-Lafuente, F. Marco et al., "Human parvovirus B19, varicella zoster virus, and human herpesvirus6 in mesenchymal stem cells of patients with osteoarthritis: analysis with quantitative real-time polymerase chain reaction," Osteoarthritis and Cartilage, vol. 15, no. 4, pp. 475-478, 2007.

[16] B. Aslan, M. S. Serin, G. Aslan et al., "Detection of parvovirus B19 in synovial fluids of patients with osteoarthritis," Diagnostic Microbiology and Infectious Diseases, vol. 60, no. 4, pp. 381-385, 2008.

[17] F. Reynier, T. Verjat, F. Turrel et al., "Increase in human endogenous retrovirus HERV-K (HML-2) viral load in active rheumatoid arthritis," Scandinavian Journal of Immunology, vol. 70, no. 3, pp. 295-299, 2009.

[18] R. Rollín, R. Álvarez-Lafuente, F. Marco et al., "The ubiquitinproteasome pathway and viral infections in articular cartilage of patients with osteoarthritis," Rheumatology International, vol. 29, no. 8, pp. 969-972, 2009.

[19] G. Freimanis, P. Hooley, H. D. Ejtehadi et al., "A role for human endogenous retrovirus-K (HML-2) in rheumatoid arthritis: investigating mechanisms of pathogenesis," Clinical and Experimental Immunology, vol. 160, no. 3, pp. 340-347, 2010.

[20] P. Nelson, H. Davari-Ejtehadi, A. Nevill, and S. Bowman, "Endogenous retrovirus Erv-3 is not implicated in rheumatoid arthritis but may provide a biomarker for osteoarthritis," Journal of Rheumatology, vol. 37, no. 2, p. 473, 2010.

[21] G. Stransky, J. Vernon, W. K. Aicher, L. W. Moreland, R. E. Gay, and S. Gay, "Virus-like particles in synovial fluids from patients with rheumatoid arthritis," British Journal of Rheumatology, vol. 32, no. 12, pp. 1044-1048, 1993.

[22] P. Gaudin, S. Ijaz, P. W. Tuke et al., "Infrequency of detection of particle-associated MSRV/HERV-W RNA in the synovial fluid of patients with rheumatoid arthritis," Rheumatology, vol. 39, no. 9, pp. 950-954, 2000.

[23] H. Stahl, B. Hubner, B. Seidl et al., "Detection of multiple viral DNA species in synovial tissue and fluid of patients with early arthritis," Annals of the Rheumatic Diseases, vol. 59, no. 5, pp. 342-346, 2000.

[24] H. D. Stahl, B. Seidl, B. Hubner et al., "High incidence of parvovirus B19 DNA in synovial tissue of patients with undifferentiated mono- and oligoarthritis," Clinical Rheumatology, vol. 19, no. 4, pp. 281-286, 2000.

[25] T. Takeda, Y. Mizugaki, L. Matsubara, S. Imai, T. Koike, and K. Takada, "Lytic Epstein-Barr virus infection in the synovial tissue of patients with rheumatoid arthritis," Arthritis and Rheumatism, vol. 43, no. 6, pp. 1218-1225, 2000.

[26] K. E. Piper, A. D. Hanssen, D. G. Lewallen et al., "Lack of detection of human retrovirus-5 proviral DNA in synovial 
tissue and blood specimens from individuals with rheumatoid arthritis or osteoarthritis," Arthritis Care and Research, vol. 55, no. 1, pp. 123-125, 2006.

[27] O. Solak, M. Altindis, H. Toktas et al., "Serologic and molecular diagnosis of human parvovirus B19 in rheumatoid arthritis patients," Turkish Journal of Rheumatology, vol. 24, no. 1, pp. 1720, 2009.

[28] C. Croia, B. Serafini, M. Bombardieri et al., "Epstein-Barr virus persistence and infection of autoreactive plasma cells in synovial lymphoid structures in rheumatoid arthritis," Annals of the Rheumatic Diseases, vol. 72, no. 9, pp. 1559-1568, 2013.

[29] E. M. McDowell and B. F. Trump, "Histologic fixatives suitable for diagnostic light and electron microscopy," Archives of Pathology and Laboratory Medicine, vol. 100, no. 8, pp. 405-414, 1976.

[30] K. T. Tokuyasu, "Application of cryoultramicrotomy to immunocytochemistry," Journal of Microscopy, vol. 143, no. 2, pp. 139149, 1986.

[31] W. Liou, H. J. Geuze, and J. W. Slot, "Improving structural integrity of cryosections for immunogold labeling," Histochemistry and Cell Biology, vol. 106, no. 1, pp. 41-58, 1996.

[32] D. J. Griffiths, C. Voisset, P. J. W. Venables, and R. A. Weiss, "Novel endogenous retrovirus in rabbits previously reported as human retrovirus 5," Journal of Virology, vol. 76, no. 14, pp. 7094-7102, 2002.

[33] P. M. Alliel, J. Périn, R. Pierig, J. Nussbaum, A. Ménard, and F. Rieger, "Endogenous retroviruses and multiple sclerosis. II. HERV-7q", Comptes Rendus de l'Academie des Sciences III, vol. 321, no. 10, pp. 857-863, 1998.

[34] F. Komurian-Pradel, G. Paranhos-Baccala, F. Bedin et al., "Molecular cloning and characterization of MSRV-related sequences associated with retrovirus-like particles," Virology, vol. 260, no. 1, pp. 1-9, 1999.

[35] J. Blond, F. Besème, L. Duret et al., "Molecular characterization and placental expression of HERV-W, a new human endogenous retrovirus family," Journal of Virology, vol. 73, no. 2, pp. 1175$1185,1999$.

[36] C. Voisset, O. Bouton, F. Bedin et al., "Chromosomal distribution and coding capacity of the human endogenous retrovirus HERV-W family," AIDS Research and Human Retroviruses, vol. 16, no. 8, pp. 731-740, 2000.

[37] M. Travnicek, J. Riman, and A. Udvardy, "Subunits of oncornavirus high molecular weight RNA. II. Detection of double stranded regions in 60S AMW (avian myeloblastosis virus) RNA," Biochemical and Biophysical Research Communications, vol. 54, no. 4, pp. 1347-1355, 1973.

[38] J. P. Leis, J. McGinnis, and R. W. Green, "Rous sarcoma virus p19 binds to specific double-stranded regions of viral RNA: effect of p19 on cleavage of viral RNA by RNase III," Virology, vol. 84, no. 1, pp. 87-98, 1978.

[39] J. J. Park and L. A. Phillips, "Isolation and purification of doublestranded RNA fragments from retrovirus RNA," Preparative Biochemistry, vol. 9, no. 3, pp. 261-272, 1979.

[40] J. C. Paillart, R. Marquet, E. Skripkin, C. Ehresmann, and B. Ehresmann, "Dimerization of retroviral genomic RNAs: structural and functional implications," Biochimie, vol. 78, no. 7, pp. 639-653, 1996.

[41] A. T. Das, B. Klaver, B. I. F. Klasens, J. L. B. van Wamel, and B. Berkhout, "A conserved hairpin motif in the R-U5 region of the human immunodeficiency virus type 1 RNA genome is essential for replication," Journal of Virology, vol. 71, no. 3, pp. 2346-2356, 1997.
[42] J. Greatorex, "The retroviral RNA dimer linkage: different structures may reflect different roles," Retrovirology, vol. 1, article 22, 2004.

[43] M. D. Moore and W. Hu, "HIV-1 RNA dimerization: it takes two to tango," AIDS Reviews, vol. 11, no. 2, pp. 91-102, 2009.

[44] N. Lukacs, "Detection of virus infection in plants and differentiation between coexisting viruses by monoclonal antibodies to double-stranded RNA," Journal of Virological Methods, vol. 47, no. 3, pp. 255-272, 1994.

[45] M. Bonin, J. Oberstraß, N. Lukacs et al., "Determination of preferential binding sites for anti-dsRNA antibodies on doublestranded RNA by scanning force microscopy," RNA, vol. 6, no. 4, pp. 563-570, 2000.

[46] D. C. Leung and M. C. Lorincz, "Silencing of endogenous retroviruses: when and why do histone marks predominate?" Trends in Biochemical Sciences, vol. 37, no. 4, pp. 127-133, 2012.

[47] M. J. Laska, K. K. Nissen, and B. A. Nexø, “(Some) cellular mechanisms influencing the transcription of human endogenous retrovirus, HERV-Fcl," PLoS ONE, vol. 8, no. 1, Article ID e53895, 2013.

[48] M. Ruebner, P. L. Strissel, A. B. Ekici et al., "Reduced syncytin1 expression levels in placental syndromes correlates with epigenetic hypermethylation of the ERVW-1 promoter region," PLoS ONE, vol. 8, no. 2, Article ID e56145, 2013.

[49] O. Schanab, J. Humer, A. Gleiss et al., "Expression of human endogenous retrovirus $\mathrm{K}$ is stimulated by ultraviolet radiation in melanoma," Pigment Cell and Melanoma Research, vol. 24, no. 4, pp. 656-665, 2011.

[50] M. Dewannieux, F. Harper, A. Richaud et al., "Identification of an infectious progenitor for the multiple-copy HERV-K human endogenous retroelements," Genome Research, vol. 16, no. 12, pp. 1548-1556, 2006.

[51] R. Contreras-Galindo, M. H. Kaplan, A. C. Contreras-Galindo et al., "Characterization of human endogenous retroviral elements in the blood of HIV-1-infected individuals," Journal of Virology, vol. 86, no. 1, pp. 262-276, 2012.

[52] T. W. Lyden, P. M. Johnson, J. M. Mwenda, and N. S. Rote, "Ultrastructural characterization of endogenous retroviral particles isolated from normal human placentas," Biology of Reproduction, vol. 51, no. 1, pp. 152-157, 1994.

[53] R. Contreras-Galindo, M. H. Kaplan, P. Leissner et al., "Human endogenous retrovirus K (HML-2) elements in the plasma of people with lymphoma and breast cancer," Journal of Virology, vol. 82, no. 19, pp. 9329-9336, 2008.

[54] H. Perron, C. Bernard, J. Bertrand et al., "Endogenous retroviral genes, Herpesviruses and gender in Multiple Sclerosis," Journal of the Neurological Sciences, vol. 286, no. 1-2, pp. 65-72, 2009.

[55] A. Serafino, E. Balestrieri, P. Pierimarchi et al., "The activation of human endogenous retrovirus K (HERV-K) is implicated in melanoma cell malignant transformation," Experimental Cell Research, vol. 315, no. 5, pp. 849-862, 2009.

[56] H. Perron, J. A. Garson, F. Bedin et al., "Molecular identification of a novel retrovirus repeatedly isolated from patients with multiple sclerosis," Proceedings of the National Academy of Sciences of the United States of America, vol. 94, no. 14, pp. 75837588, 1997.

[57] M. Garcia-Montojo, J. Varade, E. Villafuertes et al., "Expression of human endogenous retrovirus HERV-K18 is associated with clinical severity in osteoarthritis patients," Scandinavian Journal of Rheumatology, vol. 42, no. 6, pp. 498-504, 2013. 
[58] M. A. Cimmino and M. Parodi, "Risk factors for osteoarthritis," Seminars in Arthritis and Rheumatism, vol. 34, no. 6, supplement 2, pp. 29-34, 2004.

[59] M. B. Goldring and M. Otero, "Inflammation in osteoarthritis," Current Opinion in Rheumatology, vol. 23, no. 5, pp. 471-478, 2011.

[60] S. Linn, B. Murtaugh, and E. Casey, "Role of sex hormones in the development of osteoarthritis," $P M$ and $R$, vol. 4, no. 5, pp. S169-S173, 2012.

[61] F. Berenbaum, "Osteoarthritis as an inflammatory disease (osteoarthritis is not osteoarthrosis!)," Osteoarthritis and Cartilage, vol. 21, no. 1, pp. 16-21, 2013.

[62] M. Martín-Millán and S. Castañeda, "Estrogens, osteoarthritis and inflammation," Joint Bone Spine, vol. 80, no. 4, pp. 368-373, 2013.

[63] P. M. Van Der Kraan, "Understanding developmental mechanisms in the context of osteoarthritis," Current Rheumatology Reports, vol. 15, no. 6, article 333, 2013.

[64] M. Ono, M. Kawakami, and H. Ushikubo, "Stimulation of expression of the human endogenous retrovirus genome by female steroid hormones in human breast cancer cell line T47D," Journal of Virology, vol. 61, no. 6, pp. 2059-2062, 1987.

[65] A. Andersson, M. Merza, P. Venables et al., "Elevated levels of the endogenous retrovirus ERV3 in human sebaceous glands," Journal of Investigative Dermatology, vol. 106, no. 1, pp. 125-128, 1996.

[66] F. Wang-Johanning, A. R. Frost, B. Jian, L. Epp, D. W. Lu, and G. L. Johanning, "Quantitation of HERV-K env gene expression and splicing in human breast cancer," Oncogene, vol. 22, no. 10, pp. 1528-1535, 2003.

[67] S. Noorali, I. C. Rotar, C. Lewis et al., "Role of HERV-W syncytin-1 in placentation and maintenance of human pregnancy," Applied Immunohistochemistry and Molecular Morphology, vol. 17, no. 4, pp. 319-328, 2009.

[68] B. Jeong, Y. Lee, R. I. Carp, and Y. Kim, "The prevalence of human endogenous retroviruses in cerebrospinal fluids from patients with sporadic Creutzfeldt-Jakob disease," Journal of Clinical Virology, vol. 47, no. 2, pp. 136-142, 2010.

[69] E. Balestrieri, C. Arpino, C. Matteucci et al., "HERVs expression in autism spectrum disorders," PLoS ONE, vol. 7, no. 11, Article ID e48831, 2012.

[70] P. Pérot, N. Mugnier, C. Montgiraud et al., "Microarray-based sketches of the HERV transcriptome landscape," PLOS ONE, vol. 7, no. 6, Article ID e40194, 2012.

[71] H. Perron, N. Hamdani, R. Faucard et al., "Molecular characteristics of human endogenous retrovirus type-W in schizophrenia and bipolar disorder," Translational Psychiatry, vol. 2, Article ID e201, 2012.

[72] J. Blond, D. Lavillette, V. Cheynet et al., "An envelope glycoprotein of the human endogenous retrovirus HERV-W is expressed in the human placenta and fuses cells expressing the type D mammalian retrovirus receptor," Journal of Virology, vol. 74, no. 7, pp. 3321-3329, 2000

[73] M. Sha, X. Lee, X. Li et al., "Syncytin is a captive retroviral envelope protein involved in human placental morphogenesis," Nature, vol. 403, no. 6771, pp. 785-789, 2000.

[74] J. Yi, W. Lee, H. Kim, and H. Kim, "Identification of new endogenous retroviral sequences belonging to the HERV-W family in human cancer cells," Intervirology, vol. 44, no. 6, pp. 333-338, 2001.
[75] J.-M. Yi, H.-M. Kim, and H.-S. Kim, "Expression of human endogenous retrovirus HERV-W family in various human tissues and cancer cells," Journal of General Virology, vol. 85, no. 5, pp. 1203-1210, 2004.

[76] B. Bjerregaard, S. Holck, I. J. Christensen, and L. I. Larsson, "Syncytin is involved in breast cancer-endothelial cell fusions," Cellular and Molecular Life Sciences, vol. 63, no. 16, pp. 19061911, 2006.

[77] J. Gimenez, C. Montgiraud, G. Oriol et al., "Comparative methylation of ERVWE1/syncytin-1 and other human endogenous retrovirus LTRs in placenta tissues," DNA Research, vol.16, no. 4, pp. 195-211, 2009.

[78] J. M. Larsen, I. J. Christensen, H. J. Nielsen et al., "Syncytin immunoreactivity in colorectal cancer: potential prognostic impact," Cancer Letters, vol. 280, no. 1, pp. 44-49, 2009.

[79] E. Balada, M. Vilardell-Tarrés, and J. Ordi-Ros, "Implication of human endogenous retroviruses in the development of autoimmune diseases," International Reviews of Immunology, vol. 29, no. 4, pp. 351-370, 2010.

[80] L. Larsson, B. Bjerregaard, L. Wulf-Andersen, and J. F. Talts, "Syncytin and cancer cell fusions," The Scientific World Journal, vol. 7, pp. 1193-1197, 2007.

[81] K. Matsuura, T. Jigami, K. Taniue et al., "Identification of a link between Wnt/ $\beta$-catenin signalling and the cell fusion pathway," Nature Communications, vol. 2, no. 1, article 548, 2011.

[82] J. M. Antony, A. M. DesLauriers, R. K. Bhat, K. K. Ellestad, and C. Power, "Human endogenous retroviruses and multiple sclerosis: Innocent bystanders or disease determinants?" Biochimica et Biophysica Acta, vol. 1812, no. 2, pp. 162-176, 2011.

[83] A. M. Deslauriers, A. Afkhami-Goli, A. M. Paul et al., "Neuroinflammation and endoplasmic reticulum stress are coregulated by crocin to prevent demyelination and neurodegeneration," Journal of Immunology, vol. 187, no. 9, pp. 4788-4799, 2011.

[84] J. F. Woessner Jr. and M. G. Selzer, "Two latent metalloproteases of human articular cartilage that digest proteoglycan," Journal of Biological Chemistry, vol. 259, no. 6, pp. 3633-3638, 1984.

[85] W. Pruzanski, E. Bogoch, M. Wloch, and P. Vadas, "The role of phospholipase $\mathrm{A}_{2}$ in the physiopathology of osteoarthritis," Journal of Rheumatology, vol. 27, pp. 117-119, 1991.

[86] A. Shimazaki, M. O. Wright, K. Elliot, D. M. Salter, and S. J. Millward-Sadler, "Calcium/calmodulin-dependent protein kinase II in human articular chondrocytes," Biorheology, vol. 43, no. 3-4, pp. 223-233, 2006.

[87] L. Leistad, A. J. Feuerherm, A. Faxvaag, and B. Johansen, "Multiple phospholipase A2 enzymes participate in the inflammatory process in osteoarthritic cartilage," Scandinavian Journal of Rheumatology, vol. 40, no. 4, pp. 308-316, 2011. 


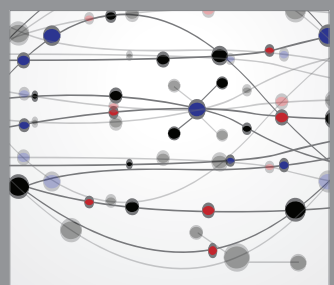

The Scientific World Journal
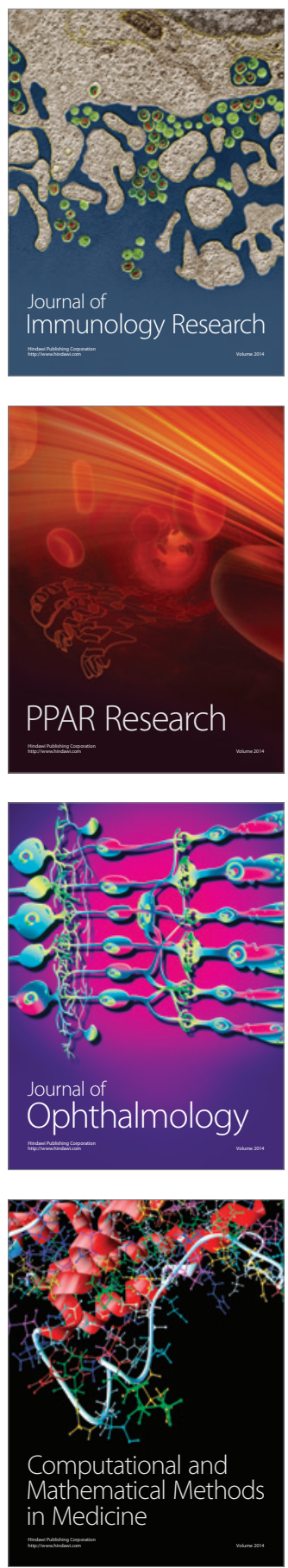

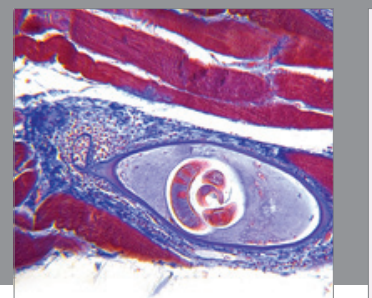

Gastroenterology

Research and Practice
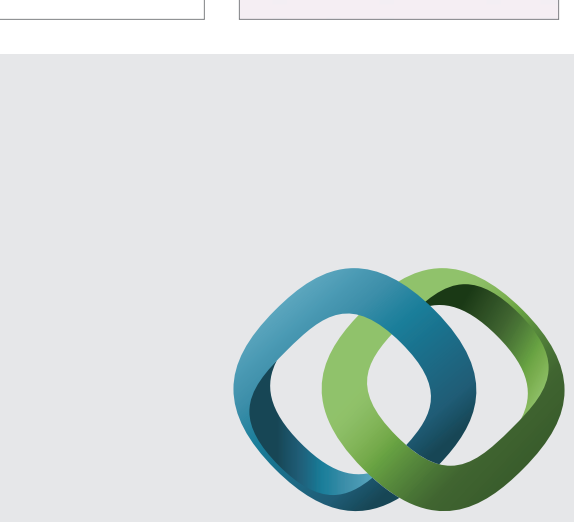

\section{Hindawi}

Submit your manuscripts at

http://www.hindawi.com
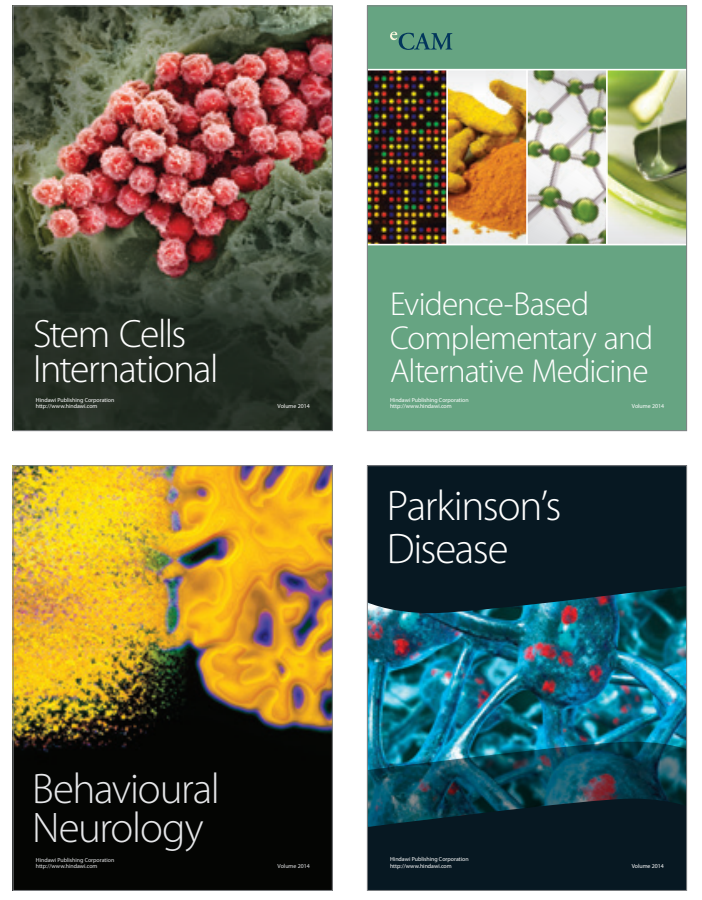
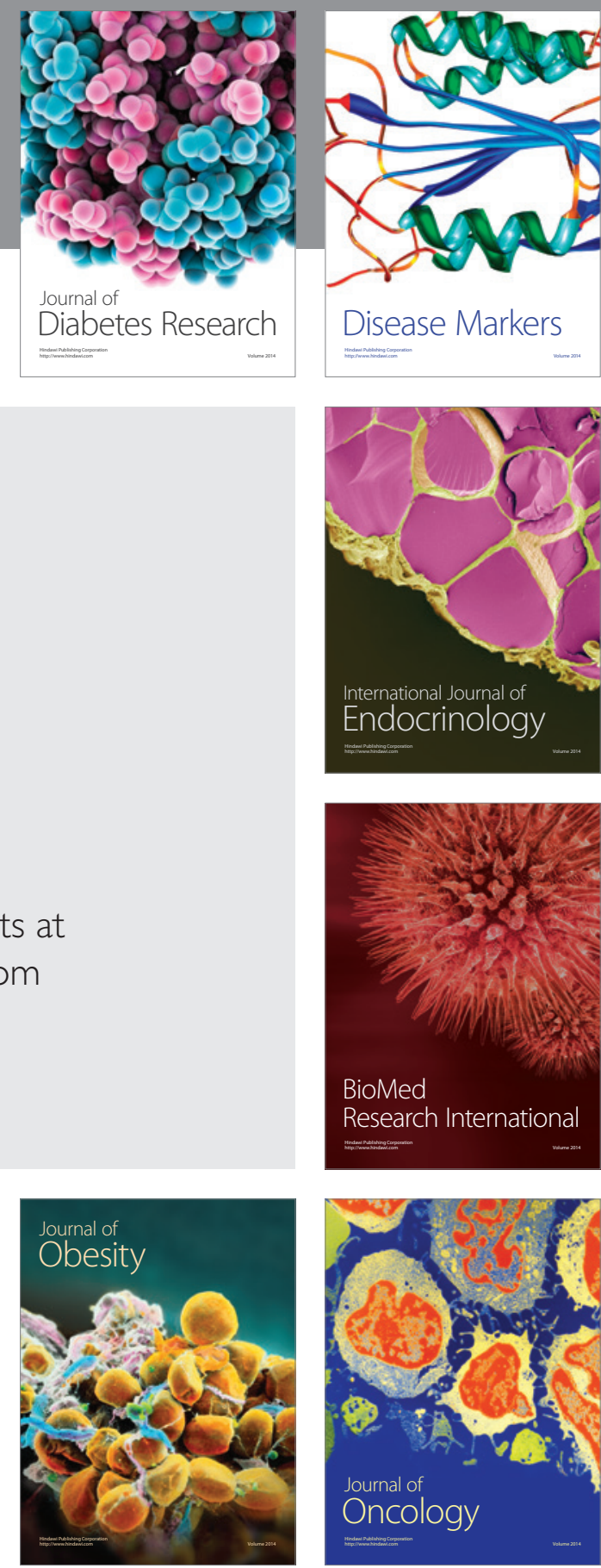

Disease Markers
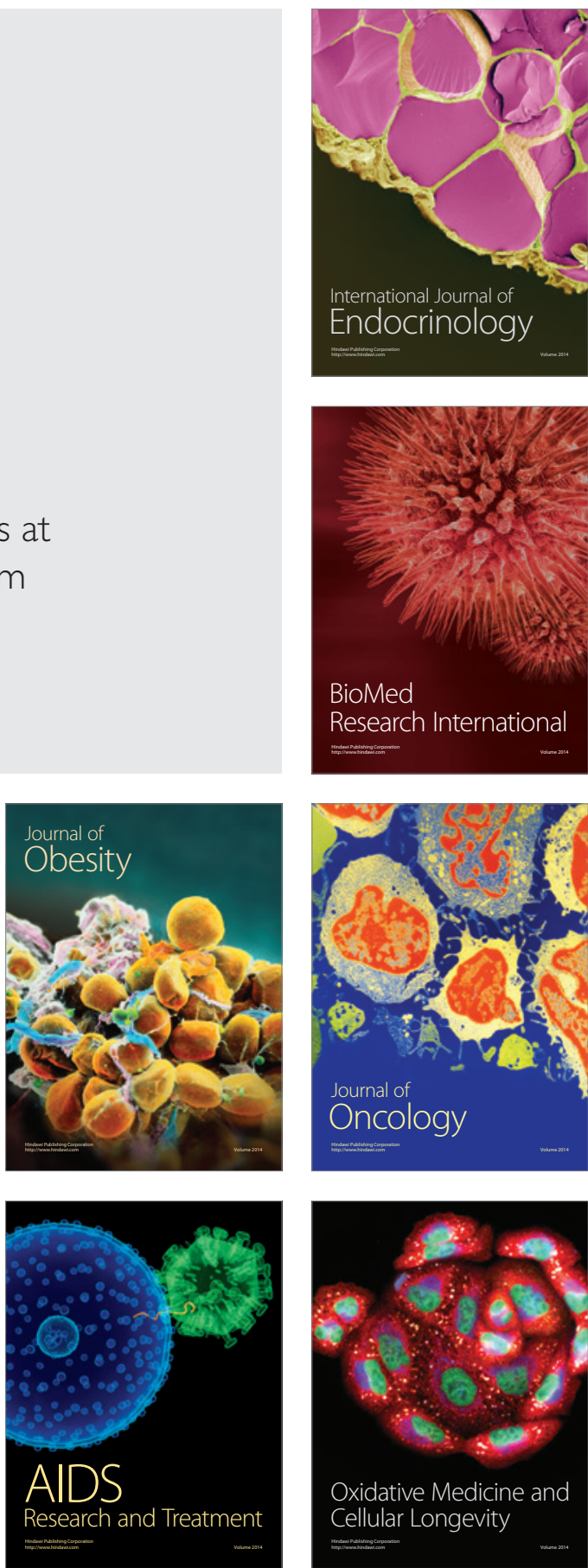